\title{
Migration Flows and Quality of Life in a Metropolitan Area: the Case of Barcelona-Spain
}

\author{
Alessandra Faggian • Vicente Royuela
}

Received: 12 March 2008 / Accepted: 18 May 2010

(C) Springer Science+Business Media B.V./

The International Society for Quality-of-Life Studies (ISQOLS) 2010

\begin{abstract}
The phenomenon of human migration is certainly not new and it has been studied from a variety of perspectives. Yet, the attention on human migration and its determinant has not been fading over time as confirmed by recent contributions (see for instance Cushing and Poot 2004 and Rebhun and Raveh 2006). In this paper we combine the recent theoretical contributions by Douglas (1997) and Wall (2001) with the methodological advancements of Guimarães et al. (2000, 2003) to model inter-municipal migration flows in the Barcelona area. In order to do that, we employ two different types of count models, i.e. the Poisson and negative binomial and compare the estimations obtained. Our results show that, even after controlling for the traditional migration factors, QoL (measured with a Composite Index which includes numerous aspects and also using a list of individual variables) is an important determinant of short distance migration movements in the Barcelona area.
\end{abstract}

Keywords Migration - Metropolitan areas · Barcelona - Spain · Poisson models · Negative Binomial models · Overinflation

\section{Introduction}

The phenomenon of human migration is certainly not new and it has been studied from a variety of perspectives. ${ }^{1}$ Yet, the attention on human migration and its

\footnotetext{
${ }^{1}$ See Michalos (1996) for a review

A. Faggian

School of Geography, University of Southampton, Highfield. Southampton SO17 1BJ England, UK e-mail: A.Faggian@soton.ac.uk

V. Royuela $(\bowtie)$

Grup d'Anàlisi Quantitativa Regional (AQR-IREA), Departament d'Econometria, Estadística i Economia Espanyola, Universitat de Barcelona,

Avda. Diagonal, 690. 08034 Barcelona, Spain

e-mail: vroyuela@ub.edu
} 
determinant has not faded over time as confirmed by recent contributions (e.g. Cushing and Poot 2004; Rebhun and Raveh 2006). So, why do people move from one place to another? Freely mobile voter-consumers decide where to live based on their evaluation of the overall quality of life (from now on referred to as QoL) offered by different locations. In other words, as Tiebout (1956) pointed out, they "vote with their feet". What it is still not clear, however, is what the most important component of QoL is in the decision to migrate.

Two distinct approaches have been 'battling' over the years on this point. On one side, in keeping with the pioneering work performed by Hicks (1932), the "disequilibrium" model of migration (e.g. Greenwood 1975, 1985; Greenwood et al. 1991; Evans 1990, 1993) assumes that migration is a "function of spatial differentials in economic opportunities" (Hunt 1993). Migration is mainly seen as a "by product" of employment search. Wages and unemployment rates differ among regions and people react to these regional differences by migrating to areas where wages are higher, and unemployment lower. The migration process is a means to restore equilibrium over space. The flow of people from low-wage to high-wage regions is accompanied by a flow of capital (if wages and the marginal productivity of capital are inversely correlated) in the opposite direction so that eventually the interregional market equilibrium is restored. Interregional migration flows are expected to slow down over time as we approach the equilibrium.

Although the disequilibrium model seemed to conform to common-sense, two problems became apparent over time. Firstly, the empirical studies linked to them found an "embarrassing number of unhypothesized signs, with people migrating in large numbers to areas of low income and to high-unemployment destinations" (Knapp and Graves 1989). Secondly, while the model predicted convergence among areas, disparities remained quite persistent casting doubt on the role of migration movements as 're-equilibrating' mechanism. To reply to these critiscisms, the supporters of the disequilibrium approach (e.g. Evans 1990) pointed out that the presence of short-term 'rigidities' in the supply of land and housing makes migration flows too slow and weak to eliminate inter-regional wage and unemployment differentials (e.g. Blackaby and Manning 1990a, b; Hughes and McCormick 1987; Bover et al. 1989 for the case of the UK) and, as such, although regional economies are indeed moving towards the equilibrium there are considerable lags in this process. These lags are shorter for young highly-skilled migrants ${ }^{2}$ but longer for older less skilled workers. A similar point was raised by Straszheim (1975) who emphasised that the house market is very slow in responding to changes in economic conditions, due to the existence of heterogeneity, a very segmented demand and a fixed short run land supply. As a consequence, the housing market is never fully adjusted, but rather somewhere on the dynamic path towards equilibrium (see Watkins 2001).

The alternative approach, also known as "equilibrium" model of migration, mainly stemmed from the work by Graves and his followers in the 1980s (e.g. Graves 1980, 1983; Knapp and Graves 1989; Schachter and Althaus 1989, 1993; Ferguson et al. 2007). The basic idea behind the equilibrium approach is that

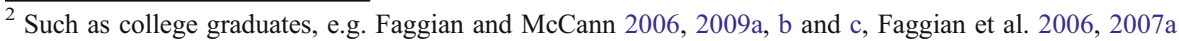
and $b$
} 
locations differ not only with respect to labour market conditions, but also, and maybe most importantly, with respect to non-tradable location-specific goods (or 'amenities'). As such, differences in wages are partly "compensating" in nature in the sense that people are paid more because their jobs are located in places with a generally lower level of amenities or "quality of life". The value of amenities is also capitalised in house rents and prices although the extent to which this capitalisation occurs is also source of debate. If house rents/prices capitalise QoL differentials perfectly, then spatial equilibrium can be assumed and migration should be either inexistent or, at most, negligible as moving would neither improve household utility nor reduce firm costs (Rosen 1974, 1979). Estimating wage income and housing expenditures as function of amenities is often used to estimate quality-of-life levels (Blomquist et al. 1988; Gyourko and Tracy 1991; Stover and Leven 1992; Gabriel et al. 2003, Berger et al. 2008).

Our view is that the disequilibrium and equilibrium approaches are not irreconcilable. Even if society is moving towards interregional equilibrium (as the disequilibrium theory argues), the adjustment to localised QoL factors is very slow. Hence, when studying migration flows it is important to consider these factors alongside the more traditional economic variables such as employment opportunities, income and wage levels.

The aim of our paper is twofold. Firstly, we want to study the determinants of inter-municipal migration in the Barcelona area and assess whether QoL is important in redistributing the population across different locations. Secondly, we test whether our results change significantly when we use different 'measures' of QoL. As Wish (1986) pointed out, one of the crucial features of QoL is its multidimensionality, which, in turn, makes it very difficult to properly measure it. While some authors (Liu 1978) prefer more aggregated indicators to summarise QoL, others (Gyourko et al. 1999; Becker et al. 1987) are sceptical of composite measures and prefer a set of individual variables. It is difficult, a priori, to determine which approach should be preferred as they both have obvious advantages and disadvantages. We, therefore, compare and contrast the results of our model when we measure QoL at three different levels of aggregation: one aggregated single indicator, three components and a list of disaggregated individual variables.

\section{Theoretical Framework}

Our theoretical model follows from the work of Douglas and Wall (1993), Douglas (1997), Wall (2001) and Guimarães et al. (2000, 2003).

Wall (2001) and Douglas (1997) developed a theoretical model in which each individual decides whether to move to another location by comparing the utility of the current location (origin) to that of an alternative location (destination). The utility of the $i$-th location for the $k$-th individual can be formally expressed as:

$$
U_{i}^{k}=u\left(A_{i}, E_{i}\right)+\varepsilon_{i}^{k}
$$

where the total utility $U$ includes a deterministic part $u$, 'common' to all individuals (i.e. on which there is 'consensus' among people) and a stochastic part $\varepsilon_{i}^{k}$ (with 
expected value equal to zero by assumption) which reflects individual idiosyncratic tastes. The 'common' part $u$ is, in turn, function of a vector of amenities $\left(A_{i}\right)$, a vector of economic variables $\left(E_{i}\right)$.

Let us assume each individual, $k$, can freely migrate from location $i$ (origin) to location $j$ (destination). If the individual decides to migrate to $j$, then we define the variable $M_{i j}^{k}$ being equal to 1 ( 0 otherwise). The probability that a randomly selected resident of $i$ migrates to $j$ can be expressed as a function of the difference in utility between the destination and the origin, the moving costs $\left(C_{i j}\right)$, and the utility differentials between $j$ and the all the other possible $r$ alternative locations. ${ }^{3}$

$$
\operatorname{Pr}\left(M_{i j}^{k}=1\right)=F\left(U_{j}-U_{i}-C_{i j}, U_{j}-U_{1}-C_{i j}+C_{j 1}, \ldots, U_{j}-U_{r}-C_{i j}+C_{j r}\right) \quad \text { with } r \neq i
$$

By defining $\Delta_{j i}^{k}$ as being equal to the difference in the expected values of the idiosyncratic components associated to two alternative locations for individual $k$, i.e. $\Delta_{j i}^{k}=E\left(\varepsilon_{j}^{k}\right)-E\left(\varepsilon_{i}^{k}\right)$ and assuming a linear functional form, we can re-write Eq. 2 as:

$$
\operatorname{Pr}\left(M_{i j}^{k}=1\right)=\alpha\left(u_{j}-u_{i}-C_{i j}+\Delta_{j i}^{k}\right)+\beta\left(\sum_{r=1}^{R} u_{j}-u_{r}-C_{i j}+C_{j r}+\Delta_{j r}^{k}\right) \quad \text { with } r \neq i
$$

The probability of moving from $i$ to $j$ is strictly increasing in the 'common' part of utility of location $j$ and strictly decreasing in the 'common' part of utility associated with location $i$ and moving costs. ${ }^{4}$

The estimation of Eq. 3 is problematic for two reasons. Firstly, it is at an 'individual' level, while most migration statistics are at a more 'aggregate' level (such as regions, municipalities etc.). And secondly, we need appropriate 'aggregation procedures' across locations belonging to the same region (or municipality in our case) to make results robust and consistent. As there is no information on intra-municipality location differences, Wall (2001) recognises the need to assume that the basic 'common' part of the utility is similar across all different locations within the same region $j$, so that only individual-specific evaluations (the idiosyncratic part of utility) differ. In our specific case this means that the number of migrants from location $i$ belonging to municipality $A$ to location $j$ belonging to municipality $B, M_{i j}$, can be re-written as:

$$
E\left(M_{i j}\right)=L_{j} \sum_{k=1}^{P_{i}} \operatorname{Pr}\left(M_{i j}^{k}=1\right)
$$

\footnotetext{
${ }^{3}$ Following Wall (2001) any individual-specific cost of moving is included in the idiosyncratic term.

${ }^{4}$ Equations 2 and 3 imply that if a location (let us call it $l$ ) is getting worse, there will be an increase in the probability of moving from $i$ to $j$, not because of an increase in the 'absolute' utility associated with location $j$, but rather the 'relative' increase in utility of this location compared to $l$.
} 
Where $L_{j}$ is the size location $j$ (measured either in terms of population or housing opportunities), and $P_{i}$ is the population of the origin $i$. Wall (2001) demonstrates that, if $P_{i}$ is large enough, Eq. 4 approaches:

$$
E\left(M_{i j}\right)=L_{j} P_{i} \operatorname{Pr}\left(M_{i j}^{k}=1\right)
$$

Rearranging the terms this is equivalent to:

$$
\operatorname{Pr}\left(M_{i j}^{k}=1\right)=E\left(\frac{M_{i j}}{L_{j} P_{i}}\right)=E\left(m_{i j}\right)
$$

where $m_{i j}$ can be interpreted as an index of "migration opportunities" that the residents in $i$ have across the locations in area $j$. The second problem with estimating Eq. 3 relates to the fact that it includes all the possible alternative locations (different from the origin and the destination).

The first problem is normally solved by using net migration flows (see Douglas 1997; Wall 2001) instead of gross migration flows with the assumption that this is an acceptable linear approximation of Eq. 3 where $\beta$ is negligible. Guimarães et al. $(2000,2003)$ propose using a discrete choice model as a starting point instead of the traditional linear OLS. They show that the number of choices in a conditional logit is equal to the number of observations in a Poisson regression, so that, under certain conditions, estimating a model for individuals where every person can migrate to a number of municipalities is equivalent to estimating a model which simply counts how many people migrate to each municipality. The second approach is much easier to implement econometrically.

As a Poisson variable is equal to a very large sum of very small probabilities, Eq. 2 can be re-written as:

$$
\begin{aligned}
\operatorname{Pr}\left(Y_{i j}=M_{i j}\right) & =F\left(u_{j}-u_{i}-C_{i j}+\Delta_{j i}^{k}, \ldots, u_{j}-u_{r}-C_{i j}+C_{j r}+\Delta_{j r}^{k}, P_{i}, L_{j}\right) \\
& =\frac{e^{-M_{i j}} \mu_{i j}^{M_{i j}}}{M_{i j} !}
\end{aligned}
$$

where $Y_{i j}$ is a random Poisson distributed variable with parameter $\mu_{i j}$ defined as:

$$
\mu_{i j}=\exp (\eta)=F\left(u_{j}-u_{i}-C_{i j}, P_{i}, L_{j}\right)
$$

In Eq. 8, similarly to Eq. 3, migration flows between $i$ and $j$ increase with an increase in 'common' utility differentials between destination and origin (in turn dependent upon amenities and economic variables), a decrease in moving costs and an increase in "migration opportunities" (in turn function of the size of the origin and the amount of locations in the municipality chosen as destination).

One of the main problems of the Poisson distribution is that it assumes the equality between mean and variance (equidispersion) or analytically:

$$
\mu_{i}=\exp \left(\mathbf{x}_{i} \beta\right)=E\left[y_{i} \mid \mathbf{x}_{i}\right]=\operatorname{Var}\left[y_{i} \mid \mathbf{x}_{i}\right]
$$

where $\mathbf{x}_{i}$ is the vector of explanatory variables.

This can be a problem as it does not fit most real data. Very often data shows overdispersion, i.e. a variance (spread of data) well above the value of the mean 
(central tendency). In other words, values in the tails (either very high or very low) are more common than what predicted by the Poisson theoretical distribution. As such, the conventional Poisson mean-variance restriction may produce seriously biased parameter estimates (see Cameron and Trivedi 1998; Wang et al. 1996).

One alternative is to use mixture models. These models explicitly model heterogeneity among observations by adding an extra parameter, which is a function of unobserved heterogeneity. In other words the mean in Eq. 9 is replaced by:

$$
\mu_{i}^{*}=\exp \left(\mathbf{x}_{i} \beta\right) \exp \left(\varepsilon_{i}\right)
$$

The negative binomial model is a specific case of mixture models in which $\exp \left(\varepsilon_{i}\right)$ is supposed to be drawn from a gamma distribution so that the probability density is:

$$
\operatorname{Pr}(y=M=\mathbf{x})=\frac{\Gamma\left(y+\alpha^{-1}\right)}{y ! \Gamma\left(\alpha^{-1}\right)}\left[\frac{\alpha^{-1}}{\alpha^{-1}+\mu}\right]^{\alpha^{-1}}\left[\frac{\mu}{\alpha^{-1}+\mu}\right]^{y}
$$

where $\Gamma$ indicates the standard gamma function and $\alpha$ determines the degree of dispersion in the predictions (the larger $\alpha$, the more spread are the data). If $\alpha=0$, the binomial negative model reduces to the Poisson regression model.

\section{Case Study}

The empirical analysis focuses on the province of Barcelona, which is one of the four provinces of the Catalonia region. Catalonia, ${ }^{5}$ located in the North-East of the country, is one of Spain's most developed regions and it is divided into four administrative provinces (NUTS III) of which Barcelona is the most densely populated one (with $76 \%$ of the region's total inhabitants, i.e. 4,628,277 in 1996). Together with Madrid, Barcelona is Spain's most populated and urbanised province. Barcelona itself is, in turn, subdivided into 314 municipalities (NUTS V classification), which are the basic unit of analysis in our study. The province includes, in hierarchical order: 11 administrative groups, called "comarcas", 24 urban systems, 48 urban subsystems ${ }^{6}$ and, of course, the mentioned 314 municipalities.

It is important to notice that a substantial part of the total population of Barcelona is concentrated in a small number of areas: ${ }^{7} 33 \%$ of the total population of the province lives in the city of Barcelona itself. ${ }^{8}$ Urban areas are mainly concentrated in the outskirts of the city of Barcelona, while more rural areas are located further away (as it is the case for most European cities). ${ }^{9}$

\footnotetext{
${ }^{5}$ NUTS II in the European administrative classification.

${ }^{6}$ These systems and subsystems are defined in Artís et al. (1999). These territorial aggregations were developed using two main criteria: commuting patterns and types of services available.

${ }^{7}$ The Gini index for the distribution of population in the different areas of the Barcelona province is equal to 0.54 confirming the fact that the population is highly concentrated in few areas.

${ }^{8}$ Data of 1996.

${ }^{9}$ In Muñiz et al. (2003) the Barcelona area has been defined as a Mediterranean polycentric city, where polycentricity comes from the large urban centre expanded its commuting area, incorporating medium sized cities that had previously been self-sufficient.
} 
Our dependent variable is the number of migration movements between pairs of municipalities. ${ }^{10}$ The data comes from Estadística de Variaciones Residenciales published by the Spanish National Statistical Institute (INE) in collaboration with the Catalan Statistical Institute (Idescat). It covers the 13-year period from 1991 to 2003. In this period the Barcelona region has experienced a strong suburbanization process (see Dura-Guimerà 2003), but we still decided to consider the whole available period to avoid short-run distortions. This approach has been followed in the past by other authors, such as Jones (2002), while other researchers pointed out that shorter periods might be preferable. ${ }^{11}$

Our final matrix of inter-municipal movements includes 98,596 cells $(314 \times 314$ municipalities). Excluding the diagonal (which represents people staying in the same municipality, for which we have no data), the final number of cells considered is 98,282 . Following a very common empirical strategy in economics (see for instance Baumol 1986 for convergence equations) and in order to avoid endogeneity issues, the explanatory variables refer to the initial 'base' year, i.e. 1991.

\section{Empirical Model and Data}

The first step to operationalise the theoretical framework into a workable empirical model is to specify the 'common' part of the utility function $(u)$. This implies both identifying the relevant economic variables and a measure of "amenities" (or QoL). There has been a plethora of definitions of QoL, some emphasising more objective components (Glaeser et al. 2001, Cheshire and Magrini 2006 among others), some highlighting the need to consider subjective factors (Chiappero Martinetti 2000) ${ }^{12}$. For the purposes of our analysis we follow the definition of Diener (2006) ${ }^{13}$ where the emphasis is more on external components ${ }^{14}$ rather than subjective well-being: "Quality of life usually refers to the degree to which a person's life is desirable versus undesirable, often with an emphasis on external components, such as environmental factors and income" (p. 401).

To measure QoL in practical terms, we follow the work by Royuela et al. (2003) where a Composite Quality of Life Index (CQLI) for the area of Barcelona was created. The composite index summarised 59 different variables organised into 17 'basic dimensions', which, in turn, were grouped into 3 main 'components' (see Table 1). The final index and the three main components are computed using a weighted arithmetic average of partial indicators that expresses the relative standardised position of every municipality after considering the variance of all variables, with a Paasche-type temporal aggregation. The index is built using equal weights for every dimension and component. The database refers to the 1991 period.

\footnotetext{
${ }^{10}$ In our analysis we have no information regarding individual characteristics.

${ }^{11}$ O'Sullivan et al. (2004) for instance proposes a 5-year period.

${ }^{12}$ For a review of this literature see for instance Lambiri et al. (2007).

13 This definition is in line with the work of Smith (1977) and Liu (1978), and also with other definitions of QoL from a more economic perspective (Mulligan et al, 2004).

14 This definition is better suited to the study of local contexts such as small cities or municipalities.
} 
Table 1 Quality of life components and their variables

\section{COMPOSITE QUALITY OF LIFE INDEX (CQLI) \\ CQLI = 1/3 IOP + 1/3 ISE + 1/3 CCL}

\section{IOP = Individual Opportunities for Progress}

$\mathrm{IOP}=0.30 \mathrm{WI}+0.25 \mathrm{LI}+0.175 \mathrm{ELI}+0.175 \mathrm{MotI}+0.10 \mathrm{DI}$

\section{WI $=$ Wealth Index}

$+\quad$ per capita available family wealth

$+\quad$ Average tax return per taxpayer

$+\quad$ Average tax paid per taxpayer

$+\quad$ per capita value added

$+\quad$ Value added growth in last five years

$\mathbf{L I}=$ Labour Index

$+\quad$ Labour activity rate

$+\quad$ Rate of unemployment

+ Gini Index of economic activity concentration

- $\quad$ GI of workers (15 sectors)

- $\quad$ GI of social security payers (10 sectors)

$+\quad$ Labour formation index

$+\quad$ Number of classes

$+\quad$ Number of students

\section{ELI= Educational Level Index}

$+\quad$ Average of studied years per person

MotI $=$ Motorization Index

$+\quad$ Number of vehicles per 1,000 inhabitants

DI = Demographic Index

- Mortality rate

$+\quad$ Birth rate

$+\quad$ Average age level index

- $\quad$ Average age level in the municipality

- $\quad$ Average age level in the comarca

\section{2. $\mathrm{ISE}=$ Index of Social Equilibrium}

$\mathrm{ISE}=0.2 \mathrm{HAI}+0.2 \mathrm{SII}+0.2 \mathrm{OCI}+0.2 \mathrm{CongI}+0.2 \mathrm{SOASI}$

HAI= Housing Access Index

$+\quad$ Rate of hiring housing

$+\quad$ Last year finished houses per 1,000 inhabitants

$+\quad$ Rate of new subsidised houses

- $\quad$ House price index in the largest city in the system

SII= Sex Inequality Index

$+\quad$ Sex inequality in education levels

$+\quad$ Sex inequality in education labour activity

\section{OCI= Obligatory Commuting Index}

$+\quad$ Outside commuting index

$+\quad 1$ - rate of workers who commute to the Barcelona urban area

$+\quad 1$ - rate of students who commute to the Barcelona urban area

$+\quad$ Distance from the nearest capital (as centre of services)

\section{CongI $=$ Congestion Index}

- $\quad$ Automobile density

\section{SOASI $=$ Social and Old Age Services Index}

$+\quad$ Number of old age residences over 1,000 old age inhabitants

$+\quad$ Number of old age cultural houses over 1,000 old age inhabitants

$+\quad$ Number of old age open-day residences over 1,000 old age inhabitants 
Table 1 (continued)

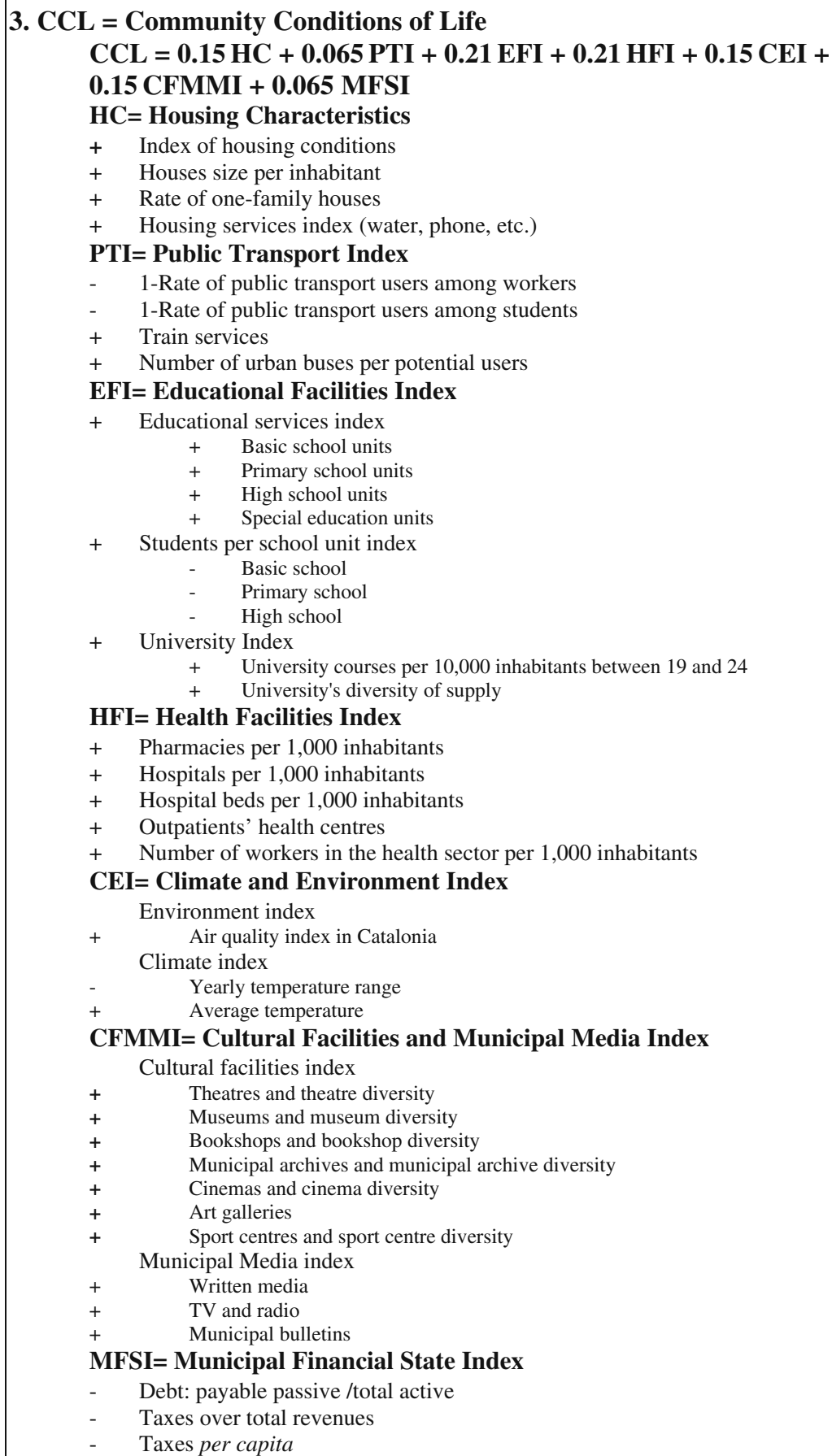


In our analysis, we use three different alternative measures of QoL: a composite index, three main 'components', and a selected list of variables. The three 'components' are:

1. Individual Opportunities for Progress (IOP): this includes individual characteristics of people living in the municipality such as wealth (WI), labour (LI), educational level (ELI), health level (DI) and mobility possibilities (MOTI).

2. Index of Social Equilibrium (ISE): this summarises 'social inequalities' in the area and includes gender inequality (SII), housing access (HAI), commuting (OCI), congestion (CONGI) and services for old people (SOASI).

3. Community Conditions of Life (CCL): this covers basic goods and services such as housing characteristics (HC), public transportation (PTI), education (EFI) and health (HFI) services, environment (CEI), culture (CFMMI), and local taxes (MFSI).

The list of the individual variables selected is shown in Table 2.

Moving costs are computed as travel time (off-peak) between origin and destination $\left(\mathrm{D}_{\mathrm{ij}}\right)$. Populations of both origins and destinations ( $\mathrm{POP}_{\mathrm{i}}$ and $\mathrm{POP}_{\mathrm{j}}$ respectively) are included as 'scale' variables (both in logarithmic terms) in the traditional 'gravity models' fashion (see Isard 1975; Isard et al. 1998; Haynes and Fotheringham 1984). We also include proxies for the hierarchical position (à la Christaller 1933) of each municipality in the more complex urban system. We use two dummy variables to show whether a municipality is head of a urban system $(\mathrm{SYS})^{15}$ or sub-system (SUB). Descriptive statistics of the variables used in the modelling process are summarised in Table 3.

Since as our focus is mainly on 'migration rates', we include a set of explanatory variables measured as differences between the value of the destination municipality $j$ and the origin municipality $i\left(X_{j i}=X_{j}-X_{i}\right)$. These are: the difference in QoL measured either using the Composite Quality of Life Indicator (Model 1), the three sub-components IOP, ISE and CCL described above (Model 2), or the list of individual variables (Model 3); and the number of telephones lines per 1,000 inhabitants (TEL) as a proxy for 'network externalities', as in Capello and Camagni (2000) and Royuela and Suriñach $(2005)^{16}$ :

Hence, the final form of Model 1 is:

$$
\begin{gathered}
M_{i j}=\beta_{0}+\beta_{1} \log \left(P O P_{i}\right)+\beta_{2} \log \left(P O P_{j}\right)+\beta_{3} \log \left(D_{i j}\right)+ \\
+\beta_{4} S U B_{i}+\beta_{5} S Y S_{i}+\beta_{6} T E L_{j i}+\delta_{1} C Q L I_{j i}+\varepsilon_{i j}
\end{gathered}
$$

Model 2 is:

$$
\begin{aligned}
M_{i j}= & \beta_{0}+\beta_{1} \log \left(P O P_{i}\right)+\beta_{2} \log \left(P O P_{j}\right)+\beta_{3} \log \left(D_{i j}\right)+ \\
& +\beta_{4} S U B_{i}+\beta_{5} S Y S_{i}+\beta_{6} T E L_{j i}+\delta_{1} I O P_{j i}+\delta_{2} I S E_{j i}+\delta_{3} C C L_{j i}+\zeta_{i j}
\end{aligned}
$$

\footnotetext{
${ }^{15}$ A municipality is head of an urban system if it is the commuting centre of an area, has a sufficient amounts of education and health facilities, and is bigger than certain size threshold (as defined in Artís et al., 1999).

16 The network city paradigm (Camagni 1993; Camagni and Di Blasio 1993) helps explain why small and/ or medium-sized cities may have higher-order functions.
} 
Table 2 List of quality of life variables

\begin{tabular}{ll}
\hline Variable & Description \\
\hline Age & Index of population age (the higher the older) \\
Air & Index of air quality \\
Temp & Average of temperature during the year \\
Cong & Congestion index (the higher the index the lower the congestion) \\
Cult & Museums per capita \\
Educ & Education units per potential alumn \\
Health & Hospital centres per capita \\
Public_t & Weight of public transportation in working commuting \\
Rent_rate & Proportion of rented houses \\
Sports & Index of sports facilities \\
Soc_serv & Third age residences \\
\hline
\end{tabular}

And Model 3 is:

$$
\begin{aligned}
M_{i j}= & \beta_{0}+\beta_{1} \log \left(P O P_{i}\right)+\beta_{2} \log \left(P O P_{j}\right)+\beta_{3} \log \left(D_{i j}\right)+ \\
& +\beta_{4} S U B_{i}+\beta_{5} S Y S_{i}+\beta_{6} \text { TEL }_{j i}+\delta_{1} \text { Age }_{j i}+\delta_{2} \text { Air }_{j i}+\delta_{3} \text { Temp }_{j i}+\delta_{4} \text { Cong }_{j i}+ \\
& +\delta_{5} \text { Cult }+\delta_{6} \text { Educ }+\delta_{7} \text { Health }_{j i}+\delta_{8} \text { Public }_{-} t_{j i}+\delta_{9} \text { Rent_rate }_{j i} \\
& +\delta_{10} \text { Sports }_{j i}+\delta_{11} \text { Social_serv }_{j i}+\zeta_{i j}
\end{aligned}
$$

\section{Estimation Results and Discussion}

Tables 4 and 5 present the results of Model 1 (Eq. 11), Model 2 (Eq. 12) and Model 3 (Eq. 13), where different QoL measures were employed. All tables compare results from both a simple Poisson regression and a Negative Binomial model. The estimated coefficients of each explanatory variable, the related standard error, and the estimated percentage point change in the dependent variable $\mathrm{M}_{\mathrm{ij}}$ for one standard deviation increase in each of the explanatory variable ${ }^{17}$ are reported.

Despite the results of the Poisson and negative binomial models being very similar, the negative binomial model performs generally better than the Poisson, as shown by the higher pseudo- $R^{2}$ value and lower Akaike, Schwarz and Hannan-Quin criteria, plus the positive and significant mixture parameter (which shows that the data are in fact overdispersed). We will, therefore, focus on the results of the negative binomial.

As expected, in all models the traditional gravitational model variables (i.e. population and distance) have the greatest influence on net migration flows. Both population variables $\left(\mathrm{POP}_{\mathrm{i}}\right.$ and $\mathrm{POP}_{\mathrm{j}}$ ) affect migration positively. The effect of

\footnotetext{
${ }^{17}$ In a linear regression, $y=a+b x$, the usual estimation of $b$ is: $b=\operatorname{COVAR}(x, y) / \operatorname{VAR}(y)$. As in the Poisson and negative binomial regressions the endogenous variable is the log of the count variable, the $\%$ StdX coefficient is a transformation of the coefficient: $\% S t d X=\mathrm{b}^{*} \mathrm{~S}(\mathrm{x})$.
} 


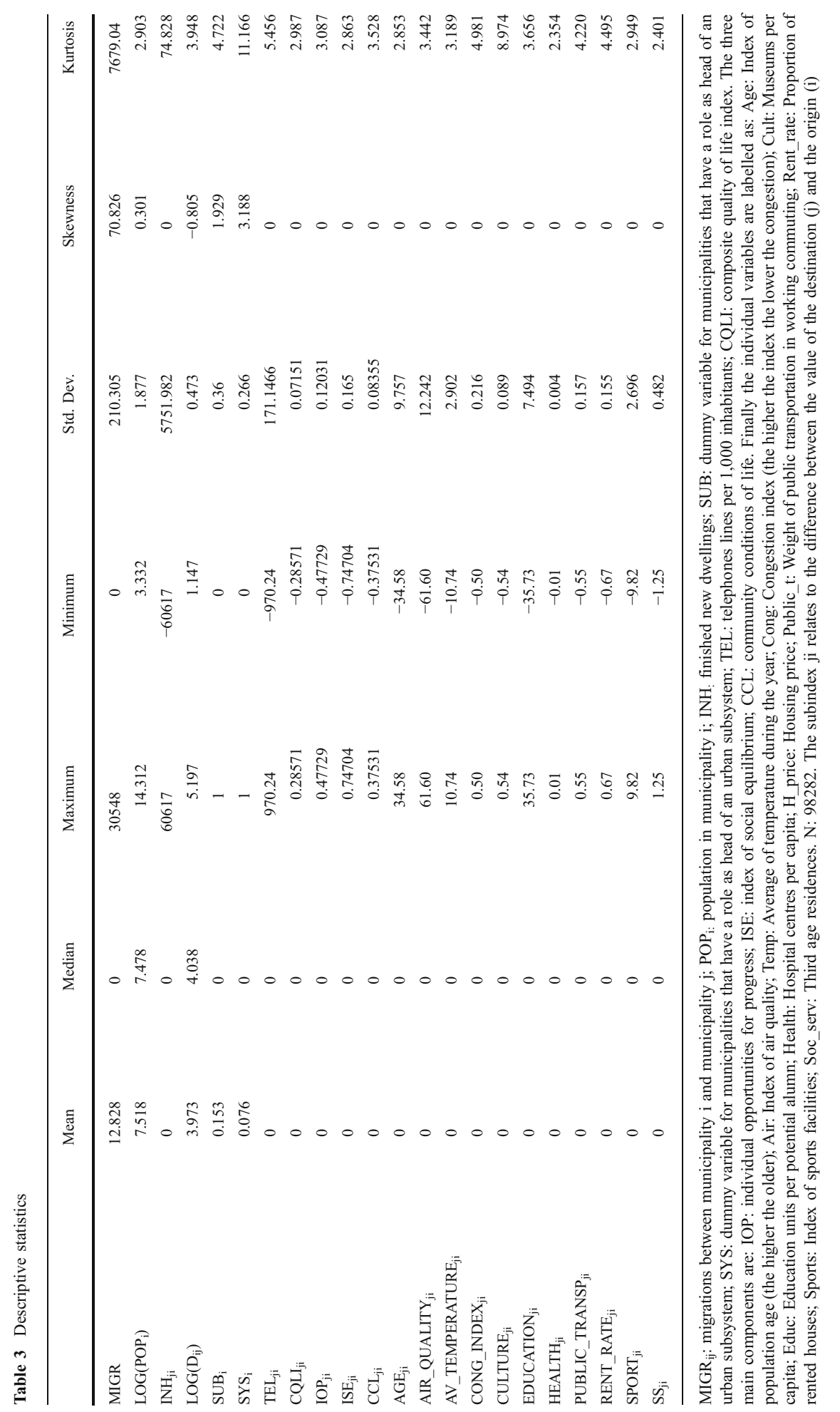




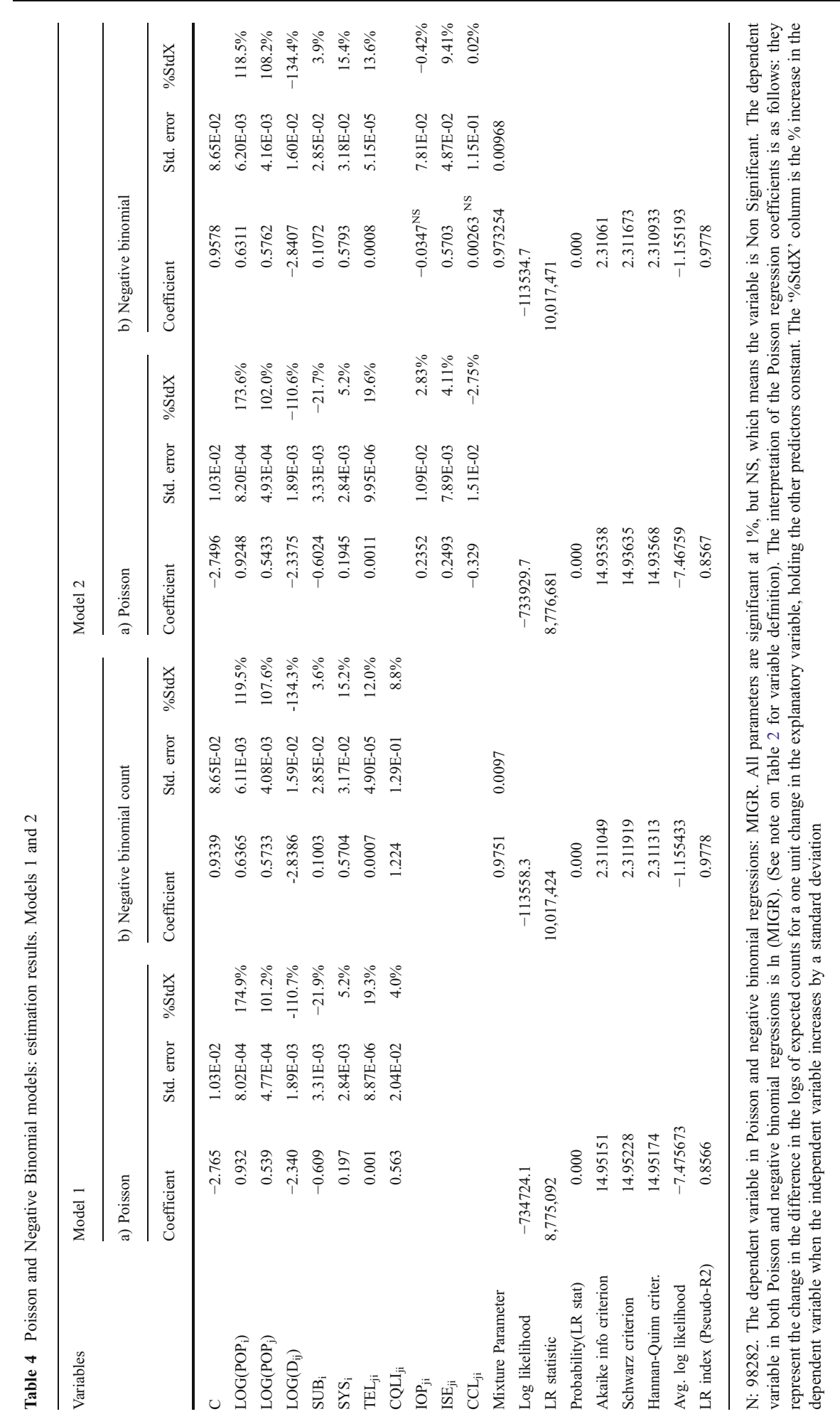


Table 5 Poisson and Negative Binomial models: estimation results. Model 3

\begin{tabular}{|c|c|c|c|c|c|c|}
\hline \multirow[t]{2}{*}{ Variables } & \multicolumn{3}{|l|}{ a) Poisson } & \multicolumn{3}{|c|}{ b) Negative binomial count } \\
\hline & Coefficient & Std. Error & $\% \operatorname{StdX}$ & Coefficient & Std. Error & $\% \operatorname{StdX}$ \\
\hline $\mathrm{C}$ & -4.179 & $1.00 \mathrm{E}-02$ & & -2.411 & $6.99 \mathrm{E}-02$ & \\
\hline $\operatorname{LOG}\left(\mathrm{POP}_{\mathrm{i}}\right)$ & 0.703 & $1.26 \mathrm{E}-03$ & $131.9 \%$ & 0.663 & $7.15 \mathrm{E}-03$ & $124.5 \%$ \\
\hline $\operatorname{LOG}\left(\mathrm{POP}_{\mathrm{j}}\right)$ & 0.640 & $1.03 \mathrm{E}-03$ & $120.1 \%$ & 0.693 & $6.14 \mathrm{E}-03$ & $130.1 \%$ \\
\hline $\operatorname{LOG}\left(\mathrm{D}_{\mathrm{ij}}\right)$ & -1.552 & $1.17 \mathrm{E}-03$ & $-73.4 \%$ & -2.225 & $1.12 \mathrm{E}-02$ & $-105.2 \%$ \\
\hline $\mathrm{SUB}_{\mathrm{i}}$ & -0.535 & $3.85 \mathrm{E}-03$ & $-19.3 \%$ & 0.149 & $2.82 \mathrm{E}-02$ & $5.4 \%$ \\
\hline $\mathrm{SYS}_{\mathrm{i}}$ & 0.217 & $3.13 \mathrm{E}-03$ & $5.8 \%$ & 0.416 & $2.91 \mathrm{E}-02$ & $11.1 \%$ \\
\hline $\mathrm{TEL}_{\mathrm{ji}}$ & 0.001 & $1.10 \mathrm{E}-05$ & $20.5 \%$ & 0.001 & $4.96 \mathrm{E}-05$ & $11.6 \%$ \\
\hline AGE & 0.0048 & $2.56 \mathrm{E}-04$ & $4.7 \%$ & $-0.0003^{\mathrm{NS}}$ & $1.44 \mathrm{E}-03$ & $-0.3 \%$ \\
\hline AIR_QUALITY & $-2.89 \mathrm{E}-04$ & $6.39 \mathrm{E}-05$ & $-0.4 \%$ & $-2.25 \mathrm{E}-03$ & $6.52 \mathrm{E}-04$ & $-2.7 \%$ \\
\hline AV_TEMPERATURE & -0.0482 & $1.05 \mathrm{E}-03$ & $-14.0 \%$ & $0.0082^{\mathrm{NS}}$ & $5.26 \mathrm{E}-03$ & $2.4 \%$ \\
\hline CONG_INDEX & -0.2698 & $6.43 \mathrm{E}-03$ & $-5.8 \%$ & 0.2064 & $4.88 \mathrm{E}-02$ & $4.5 \%$ \\
\hline CULTURE & 0.9042 & $1.30 \mathrm{E}-02$ & $8.0 \%$ & 0.5290 & $8.33 \mathrm{E}-02$ & $4.7 \%$ \\
\hline EDUCATION & 0.0056 & $1.33 \mathrm{E}-04$ & $4.2 \%$ & 0.0043 & $1.05 \mathrm{E}-03$ & $3.2 \%$ \\
\hline HEALTH & -52.0323 & $5.67 \mathrm{E}-01$ & $-22.7 \%$ & $-4.1550^{\mathrm{NS}}$ & $3.96 \mathrm{E}+00$ & $-1.8 \%$ \\
\hline PUBLIC_TRANSP & 0.7898 & $9.57 \mathrm{E}-03$ & $12.4 \%$ & 0.7698 & $6.44 \mathrm{E}-02$ & $12.0 \%$ \\
\hline RENT_RATE & -0.9750 & $1.50 \mathrm{E}-02$ & $-15.1 \%$ & $-0.1010^{\mathrm{NS}}$ & $6.87 \mathrm{E}-02$ & $-1.6 \%$ \\
\hline SPORT & 0.1107 & $8.53 \mathrm{E}-04$ & $29.8 \%$ & 0.0746 & $4.59 \mathrm{E}-03$ & $20.1 \%$ \\
\hline SS & 0.0461 & $7.32 \mathrm{E}-03$ & $2.2 \%$ & $-0.0357^{\mathrm{NS}}$ & $3.88 \mathrm{E}-02$ & $-1.7 \%$ \\
\hline Mixture Parameter & & & & 0.6610 & 0.0103 & \\
\hline Log likelihood & $-630,445$ & & & $-109,060$ & & \\
\hline LR statistic & 8983650 & & & 10026420 & & \\
\hline Probability(LR stat) & 0.000 & & & 0.000 & & \\
\hline Akaike info criterion & 12.82968 & & & 2.219714 & & \\
\hline Schwarz criterion & 12.83142 & & & 2.22155 & & \\
\hline Hannan-Quinn criter. & 12.83021 & & & 2.220272 & & \\
\hline Avg. log likelihood & -6.414655 & & & -1.109664 & & \\
\hline LR index (Pseudo-R2) & 0.8769 & & & 0.9787 & & \\
\hline
\end{tabular}

$\mathrm{N}$ : 98282. The dependent variable in Poisson and negative binomial regressions: MIGR. All parameters are significant at $1 \%$, but NS, which means the variable is Non Significant. The dependent variable in both Poisson and negative binomial regressions is $\ln$ (MIGR). (See note on Table 2 for variable definition). The interpretation of the Poisson regression coefficients is as follows: they represent the change in the difference in the logs of expected counts for a one unit change in the explanatory variable, holding the other predictors constant. The ' $\% \mathrm{StdX}$ ' column is the $\%$ increase in the dependent variable when the independent variable increases by a standard deviation

origin and destination populations is quite similar (in percentage terms), and this is particularly true in the negative binomial model. Distance between origin and destination $\left(\mathrm{D}_{\mathrm{ij}}\right)$ has a negative impact on the number of migrants, and this impact is the highest in terms of percentage point change for a standard deviation.

The dummy variables $\mathrm{SYS}_{\mathrm{i}}$ and $\mathrm{SUB}_{\mathrm{i}}$ are positive and significant, which confirms the importance of being hierarchical 'superior' in the metropolitan urban structure. Network externalities, measured by telephone lines, also have a positive and 
significant coefficient in line with expectation and with previous research work (see for instance Royuela et al. 2010 who find that network externalities play an important role in the process of growth of municipalities in the Barcelona province).

The results on QoL factors are also in line with expectations. In Model 1 QoL was proxied by a single composite index (CQLI). Its estimated coefficient is positive and significant, i.e. a higher composite index of quality of life significantly increases inter-municipality migration (increasing the CQLI by one standard deviation, increases migration by $8.8 \%$ ).

Results of Model 2, where we used the three sub-components of the CQLI, are more mixed. The Index of Social Equilibrium (ISE) becomes more important in percentage terms $(9.4 \%)$, while the other two components become statistically insignificant. It seems therefore that having a better position in the social aspect of the neighbourhoods (congestion, inequalities, or subsidized houses, among other variables) is more important than having rich and educated people (the Individual Opportunities for Progress, IOP, index) or having more Educational, Health or Cultural Services (Community Conditions of Life, CCL, index).

Finally, Model 3 includes a list of key QoL individual variables (see Table 2) without any ad-hoc mixture. Results are presented in Table 5. Including 12 individual variables increases notably the goodness of fit. In terms of sign, most of the results are as expected with five variables having positive and significant coefficients, six variables being non significant and only one variable (Air quality) being non 'wellbehaved', i.e. having a significant but negative estimated coefficient.

The variables influencing migration flows positively are: sports facilities $(20.2 \%)$, public transportation $(12.1 \%)$, culture facilities $(4.6 \%)$, lower congestion $(4.5 \%)$ and education facilities (3.3\%). On the contrary, better air quality $(-2.8 \%)$ does not positively affect migration. One of the reason might be that worse air quality is associated with higher agglomeration economies (in turn linked to job creation) which might be off-setting the air quality effect.

As for the variables with non significant coefficients, this does not necessarily mean that they play no role for movers. As we are considering inter-municipal moves, the territorial distribution of some of these key QoL variables might be relatively homogenous over the territory and this would reduce their significance as key variable for moving decisions. One example of variable which is relatively homogenous over the Barcelona metropolitan area is health facilities, which, in fact have a non significant coefficient.

\section{Conclusions}

Combining the theoretical approach by Douglas (1997) and Wall (2001) and the methodological advancements by Guimarães et al. (2000, 2003) we studied the determinants of migration flows between municipalities in the Barcelona metropolitan area for the period 1991-2003 with a particular emphasis on quality of life (QoL) factors. We found that migration flows are clearly influenced by QoL, The current confirms previous analysis developed under different perspectives, what is a prove of the robustness of our results. It implies, for whatever reason, that the spatial equilibrium of the housing markets does not compensate QoL differentials between 
locations. Besides, QoL matters irrespective if we measure it via a single composite indicator (CQLI) or with more disaggregated variables.

While QoL indices have been dismissed in the past as not being particularly useful, our results show that a single composite index, if well constructed, can be used to proxy QoL differentials among different localities, as it gives results in line with the use of more disaggregated QoL variables. Nevertheless, individual variables can be used to 'fine tune' the results and better identify which particular aspects of QoL play a more vital role in a particular territorial context.

In the case of the Barcelona metropolitan area, for instance, the most significant individual QoL variables are sport, culture, and education facilities, good public transport and lower congestion. Other QoL variables are insignificant, which could be related to the relative territorial homogeneity of these facilities over the Barcelona metropolitan area.

Also, from a more technical point of view, count models are a useful alternative to OLS based on individual observations to study inter-municipal movements. In the case of Barcelona, the clear presence of overdispersion meant that the negative binomial model was preferred to a simple Poisson. The phenomenon of overdispersion is often overlooked in empirical work, but it does constitute the rule rather than the exception when dealing with most real world data and hence should always be controlled for to avoid biases in the results.

From a policy perspective, we believe our paper shows that migration regressions should not be completely dismissed quite as yet, because they can provide useful information on what determine inter-provincial migration and ultimately population distribution in a metropolitan area. Moreover, identifying what QoL factors seem to be more heterogenously distributed over space (and hence influence migration movements more) might help planning for a better future provision of facilities in certain areas.

As we only used objective measures of QoL in this paper, one of our future research directions will be to include more subjective measurements of satisfaction especially related to housing, facilities and the local environment (as suggested by Stimson et al. 2010). We would also like to define the local environment more broadly to include the role of neighbouring areas, and also to differentiate between short, medium and long distance moves. More sophisticated spatial econometric techniques would allow us to do so in the future.

Acknowledgements This work has the support of CICYT SEJ2006-07665 project and of the Ref PR2005-0253 mobility grant of the Education and Science Ministry of Spain.

\section{References}

Artís, M., Suriñach, J., Pons, E., Romaní, J., Royuela, V., \& Reyes, M. (1999). Sistemes i Subsistemes Urbans a la Província de Barcelona, Working Paper 99-R02. Anàlisi Quantitativa Regional Research Group. Barcelona: Universitat de Barcelona y Diputació de Barcelona.

Baumol, W. J. (1986). Productivity growth, convergence, and welfare-what the long-run data show. American Economic Review, 76-5, 1072-1085.

Becker, R. A., Denby, R., McGill, R., \& Wilks, A. R. (1987). Analysis of the data from the places rated almanac. The American Statistician, 41, 169-186. 
Berger, M. C., Blomquist, G. C., \& Sabirianova Peter, K. (2008). Compensating differentials in emerging labour and housing markets: estimates of quality of life in Russian cities. Journal of Urban Economics, 63, 25-57.

Blackaby, D. H., \& Manning, D. N. (1990a). The north-south divide: questions of existence and stability. The Economic Journal, 100, 510-527.

Blackaby, D. H., \& Manning, D. N. (1990b). The north-south divide: earnings: unemployment and cost of living differences in Great Britain. Papers of the Regional Science Association, 69, 43-55.

Blomquist, G. C., Berger, M. C., \& Hoehn, J. P. (1988). New estimates of quality of life in urban areas. American Economic Review, 78-1, 89-107.

Bover, O., Muellbauer, J., \& Murphy, A. (1989). Housing, wages and UK labour markets. Oxford Bulletin of Economics and Statistics, 51(2), 97-136.

Camagni, R. (1993). From city hierarchy to city network: reflections about an emerging paradigm. In T. Lachmanan \& P. Nijkamp (Eds.), Structure and change in the space economy (pp. 60-90). Berlin: Springer Verlag.

Camagni, R., \& Blasio, D. (Eds.). (1993). Le reti di città. Milan: Franco Angeli.

Cameron, C., \& Trivedi, P. K. (1998). Regression analysis of count data. New York: Cambridge University Press.

Capello, R., \& Camagni, R. (2000). Beyond optimal city size: an evaluation of alternative urban growth patterns. Urban Studies, 37(9), 1479-1496.

Cheshire, P., \& Magrini, S. (2006). Population growth in European cities: weather matters-but only nationally. Regional Studies, 40-1, 23-37.

Chiappero Martinetti, E. (2000). A multi-dimensional assessment of well-being based on Sen's functioning theory. Revista Internationale di Scienzie Sociali, 108, 207-231.

Christaller, W. (1933). Die Zentralen Orte in Süddeutschland. Jena: Fischer.

Cushing, B., \& Poot, J. (2004). Crossing boundaries and borders: regional science advances in migration modelling. Papers in Regional Science, 83, 317-338.

Diener, E. (2006). Guidelines for national indicators of subjective well-being and ill-being. Journal of Happiness Studies, 7, 397-404.

Douglas, S. (1997). Estimating relative standard of living in the United States using cross-migration data. Journal of Regional Science, 37(3), 411-436.

Douglas, S., \& Wall, H. J. (1993). Voting with your feet and the quality-of-life index-a simple nonparametric approach applied to Canada. Economics Letters, 42(2-3), 229-236.

Dura-Guimerà, A. (2003). Population deconcentration and social restructuring in Barcelona, a European Mediterranean city. Cities, 20(6), 387-394.

Evans, A. (1990). The assumption of equilibrium in the analysis of migration and interregional differences: a review of some recent research. Journal of Regional Science, 30(4), 515-531.

Evans, A. (1993). Interregional equilibrium: a transatlantic view. Journal of Regional Science, 30, 515-531.

Faggian, A., \& McCann, P. (2006). Human capital flows and regional knowledge assets: a simultaneous equation approach. Oxford Economic Papers, 52, 475-500.

Faggian, A., \& McCann, P. (2009a). Human capital, graduate migration and innovation in British Regions. Cambridge Journal of Economics, 33, 317-333.

Faggian, A., \& McCann, P. (2009b). Universities, agglomerations and graduate human capital mobility. Journal of Economic and Social Geography, 100-2, 210-223.

Faggian, A., \& McCann, P. (2009c). Human capital and regional development. In R. Capello, \& P. Nijkamp (Eds.), Handbook of regional growth and development theories (pp. 131-151). London: Edward Elgar.

Faggian, A., McCann, P., \& Sheppard, S. C. (2006). An analysis of ethnic differences in UK graduate migration. Annals of Regional Science, 40(2), 461-471.

Faggian, A., McCann, P., \& Sheppard, S. C. (2007a). Some evidence that women are more mobile than men: gender differences in UK graduate migration behaviour. Journal of Regional Science, 47(3), $517-539$.

Faggian, A., McCann, P., \& Sheppard, S. C. (2007b). Human capital, higher education and graduate migration: an analysis of Scottish and Welsh students. Urban Studies, 44(13), 2511-2528.

Ferguson, M., Ali, K., Olfert, M. R., \& Partridge, M. D. (2007). Voting with their feet: jobs versus amenities. Growth and Change, 38(1), 77-110.

Gabriel, S. A., Mattey, J. P., \& Wascher, W. L. (2003). Compensating differentials and evolution in the quality-of-life among U.S. states. Regional Science and Urban Economics, 33, 619-649.

Glaeser, E. L., Kolko, J., \& Saiz, A. (2001). Consumer city. Journal of Economic Geography, 1-1, $27-51$. Graves, P. E. (1980). Migration and climate. Journal of Regional Science, 20(2), 227-237. 
Graves, P. E. (1983). Migration with a composite amenity: the role of rents. Journal of Regional Science, 23(4), 541-546.

Greenwood, M. J. (1975). Research on internal migration in the United States: a survey. Journal of Economic Literature, 13(2), 397-433.

Greenwood, M. J. (1985). Human migration: theory, models and empirical studies. Journal of Regional Science, 25(4), 521-544.

Greenwood, M. J., Hunt, G., Rickman, D. S., \& Treyz, G. I. (1991). Migration, regional equilibrium, and the estimation of compensating differentials. The American Economic Review, 81(5), 1382-1390.

Guimarães, P., Figueiredo, O., \& Woodward, D. (2000). Agglomeration and the location of foreign direct investment in Portugal. Journal of Urban Economics, 47, 115-135.

Guimarães, P., Figueiredo, O., \& Woodward, D. (2003). A tractable approach to the firm location decision problem. Review of Economics and Statistics, 85, 201-204.

Gyourko, J., \& Tracy, J. (1991). The structure of local public finance and the quality of life. Journal of Political Economy, 99(4), 774-806.

Gyourko, J., Kahn, M., \& Tracy, J. (1999). Quality of life and environmental conditions. In P. Chesire \& E. S. Mills (Eds.), Handbook of regional and urban economics: Volume 3, applied urban economics (pp. 1413-1454). Amsterdam: North Holland.

Haynes, K. E., \& Fotheringham, A. S. (1984). Gravity and spatial interaction models. Beverly Hills: SagePublications.

Hicks, J. R. (1932). Theory of wages. New York: MacMillan.

Hughes, G. A., \& McCormick, B. (1987). Housing markets, unemployment and labour market flexibility in the UK. European Economic Review, 31, 615-645.

Hunt, G. L. (1993). Equilibrium and disequilibrium in migration modelling. Regional Studies, 27, 341349.

Isard, W. (1975). A simple rationale for gravity model type behavior. Papers of the Regional Science Association, 35, 25-30.

Isard, W., Azis, I., Drennan, M., Miller, R., Saltzman, S., \& Thorbecke, E. (1998). Methods of interregional and regional analysis. Brookfield, Vermont: Ashgate.

Jones, C. (2002). The definition of housing market areas and strategic planning. Urban Studies, 39(3), 549-564.

Knapp, T. A., \& Graves, P. E. (1989). On the role of amenities in models of migration and regional development. Journal of Regional Science, 29(1), 71-87.

Lambiri, D., Biagi, B., \& Royuela, V. (2007). Quality of life and urban economics. Social Indicators Research, 84(1), 1-25.

Liu, B. C. (1978). Variations in social quality of life indicators in medium metropolitan areas. American Journal of Economics and Sociology, 37(3), 241-260.

Michalos, A. C. (1996). Migration and the quality of life: a review essay. Social Indicators Research, 39, $121-166$.

Mulligan, G., Carruthers, J., \& Cahill, M. (2004). Urban quality of life and public policy: A survey. In R. Capello, \& P. Nijkamp (Eds.), Urban dynamics and growth, advances in urban economics (pp. 729802). Amsterdam: Elsevier.

Muñiz, I., Galindo, A., \& García, M. A. (2003). Cubic spline population density functions and satellite city delimitation: the case of Barcelona. Urban Studies, 40(7), 1303-1321.

O’Sullivan, T., Young, G., Maclennan, D., Gibb, K., Mclaren, J., Britain, A. (2004). Local housing system analysis good practice guide. Edinburgh: Communities Scotland.

Rebhun, U., \& Raveh, A. (2006). The spatial distribution of quality of life in the United States and interstate migration, 1965-1970 and 1985-1990. Social Indicators Research, 78, 137-178.

Rosen, S. (1974). Hedonic prices and implicit markets: product differentiation in pure competition. Journal of Political Economy, 82, 34-55.

Rosen, S. (1979). Wage-based indexes of urban quality of life. In P. Mieszkowski \& M. Strazheim (Eds.), Current issues in urban economics (pp. 74-104). Baltimore: Johns Hopkins.

Royuela, V., \& Suriñach, J. (2005). Constituents of quality of life and urban size. Social Indicators Research, 74(3), 549-572.

Royuela, V., Suriñach, J., \& Reyes, M. (2003). Measuring quality of life in small areas over different periods of time. Analysis of the province of Barcelona. Social Indicators Research, 64(1), 51-74.

Royuela, V., Moreno, R., \& Vayá, E. (2010). Is the influence of quality of life on urban growth nonstationary in space? A case study of Barcelona, Regional Studies, 44(5), 551-567.

Schachter, J., \& Althaus, P. G. (1989). An equilibrium model of gross migration. Journal of Regional Science, 29(2), 143-159. 
Schachter, J., \& Althaus, P. G. (1993). The assumption of equilibrium in models of migration. Journal of Regional Science, 33(1), 85-88.

Smith, D. M. (1977). Human geography: A welfare approach. Londres: Edward Arnold.

Stimson, R. J., McCrea, R., \& Marans, R. W. (2010). Analyzing quality of urban life. Paper presented at the Annual Conference of the Western Regional Science Association, Sedona, Arizona.

Stover, M. E., \& Leven, C. (1992). Methodological issues in the determination of the quality of life in urban areas. Urban Studies, 29(5), 737-754.

Straszheim, M. R. (1975). An econometric analysis of the urban housing market, Urban and Regional Studies, 2. New York: NBER.

Tiebout, C. M. (1956). A pure theory of local expenditures. Journal of Political Economy, 64, 416-424.

Wall, H. J. (2001). Voting with your feet in the United Kingdom: using cross-migration rates to estimate relative living standards. Papers in Regional Science, 80, 1-23.

Wang, P., Puterman, M. L., Cockburn, I., \& Le, N. (1996). Mixed Poisson regression models with covariate dependent rates. Biometrics, 52, 381-400.

Watkins, C. (2001). The definition and identification of housing submarkets. Environment and Planning A, 33, 2235-2253.

Wish, N. D. (1986). Are we really measuring the quality of life? Well-being has subjective dimensions, as well as objective ones. American Journal of Economics and Sociology, 45(1), 93-99. 